\title{
Physical Education Reform and Development in Regular Institutions of Higher Learning under the Vision of Modern Great Education
}

\author{
Zhonghui $\mathrm{He}^{*}$, Guangan Hao \\ Department of Physical Education, Peking University, Beijing, China \\ Email: "hezhh@pku.edu.cn
}

Received November $13^{\text {th }}$, 2013; revised December 13 ${ }^{\text {th }}$, 2013; accepted December $20^{\text {th }}, 2013$

\begin{abstract}
Copyright (c) 2014 Zhonghui He, Guangan Hao. This is an open access article distributed under the Creative Commons Attribution License, which permits unrestricted use, distribution, and reproduction in any medium, provided the original work is properly cited. In accordance of the Creative Commons Attribution License all Copyrights (c) 2014 are reserved for SCIRP and the owner of the intellectual property Zhonghui He, Guangan Hao. All Copyright @ 2014 are guarded by law and by SCIRP as a guardian.
\end{abstract}

\begin{abstract}
In the world's largest higher-education system, constant improvement of quality is the lifeline of higher education, and it always runs through all kinds of works of the higher learning institutions, such as talent training, scientific research, social services, and cultural inheritance and innovation. "Great Education Concept" of higher learning institutions is to put college students under the comprehensive social and school developmental environment and to take into account the multiple talent cultivation relations of society and family, society and school while making the external environment of teaching in class and extracurricular activities compatible. Implement integral measures for multiple cultivation of college student in morality, intelligence and sports, and continually provide socialist modernization construction with powerful talent guarantee and intellectual support. In order to improve education quality, to carry on sunshine sports and to enhance students' physical quality, there is a need of constant reform and innovation: improving the teaching evaluation system through "General Student Sports Level Standard”; promoting physical quality monitoring management through physical health management platform; improving physical health level through development of sports community; stressing on students' self education; paying attention to all-round development, and promoting development and prosperity of the university campus sport culture. To deepen sport reform in institutions of higher learning via the three means is an effective measure of physical education reform and development of higher learning institutions under the great education concept.
\end{abstract}

Keywords: Great Education Concept; Regular Institutions of Higher Learning; Physical Education Reform

\section{Trend of Development and Challenges of China's Higher Education in the New Period}

In his "Speech for Celebration of the 100th Founding Anniversary of Tsinghua University”, President Hu Jintao pointed out that: the world today is in a period of greater development, transformation and adjustment. The world multi-polarization and economic globalization gain further momentum, world economic situation experiences new changes, competition in overall national strength and all kinds of forces become more intense, and the worldwide productivity, means of production, ways of life, and social economic development pattern are undergoing profound changes. Especially, innovation has become the main driving force of economic and social development, and knowledge innovation has become the key element of national competitiveness.

As the important juncture of science and technology-the first productive forces and talent-the first resources, higher education has a very important position and role in national development. Since founding of the New China 60 years ago, especially the reform and opening-up 30 years ago, China has

\footnotetext{
*Corresponding author.
}

built the world's largest higher education system, cultivated hundreds of millions of high-level professional talents and personnel with high technical ability, and gained a batch of world advanced scientific and technological achievements. At the same time, from the general point of view, China's higher education still cannot completely adapt to the requirements of economic and social development and people's reception of a good education, and compared with the world advanced standard, there is still a significant gap. To continuously improve quality has been the lifeline of higher education, and it must run through all the endeavors of higher learning institutions, such as talent training, scientific research, social services, and cultural inheritance and innovation.

"Great Education Concept" of higher learning institutions is to put college students under the comprehensive social and school developmental environment and to take into account of the multiple talent cultivation relations of society and family, society and school while making the external environment of teaching in class and extracurricular activities compatible. Implement integral measures for multiple cultivation of college student in morality, intelligence, and sports continually provide socialist modernization construction with powerful talent guar- 
antee and intellectual support.

Means and Measures of PE Reform and Development of Regular Institutions of Higher Learning-Case of PE Teaching Reform of Peking University

Improve the Quality of Higher Education in an All-Round Way_Promoting "General Student Sports Level Standard"

\section{Reform Background and Reasons}

In the "National Outline for Medium- and Long Term Educational Reform and Development (2010-2020)", it is explicitly pointed out that: "improve quality as the core task of education reform and development. Build the scientific outlook on quality, and take promotion of all-round development of man and adaptation of society need as the fundamental standard for education quality measurement". The higher education development outlook takes improvement of quality as the core, "establish education quality national standards, set up and improve education quality security system. Strengthen teacher team construction, and improve teachers' overall quality".

In recent years, especially since implementation of the "Physical Education Curriculum Guiding Outline for Common Institutions of Higher Learning in China" of 2002, PE teaching reform in higher learning institutions with "people-orientation, health first" as guiding ideology has been carried out in a deeper way, and in order to improve students' autonomy and enrich the course of sports curriculum, more and more sports projects have been set up in higher learning institutions. However, there are concomitant problems. First, there is the curriculum evaluation problem as that teaching program cannot realize synchronous development with evaluation and the lack of curriculum evaluation results in that the quality of physical education teaching in higher learning institutions can't get effective guarantee. Secondly, increase of teaching program also results in the continuous increase of skilled programs of teachers required to be competent for the teaching position; teachers should undergo continuous in-service education and training and learn new sports skills. However, because of insufficient understanding of new programs by sports teachers and the general lack of a perfect reserve of theory, skills and concepts, they are in urgent need of study and training, or take up posts to teach new curriculum even without training. On the whole, the overall quality of teachers' team still cannot fully adapt to the need of education reform and development of the new period.

\section{Measures and Effects}

The "Common Student Sports Level Standard" is a system in view of common student sports level evaluation, established in reference with the professional athlete technical level system of the General Administration of Sport of China and in connection with the actual school situation. For ordinary students, the measurement of the degree of their mastery of the sports items is the important reference basis to attract students to master, get familiar with, and improve their sports skills during their school period. It is also an important basis to measure teachers' teaching skills, and also criterion to assess teacher's sports skills and teaching ability.

Implementation of the "Common Student Sports Level Standard" is based on the principle of single classroom teaching as its basis, and through teaching evaluation, assess the sports level of students; with campus events as priority and creation of new events as supplementary, assess the sports level of students through the performance of various events; the process of implementation is dominated by the Department of Physical Education, with sports societies or associations and units of college and department as the main body. The process of implementation of the "Common Student Sports Level standard" includes: 1) classroom teaching evaluation; 2) sports culture festival; 3) sports society or association activities; 4) level-classification competition; 5) intra-college or department event competition, and inter-school event competition.

\section{Reform Results}

At present, Peking University, Shenzhen University, and Hebei University have already implemented the "Common Student Sports Level Standard” in their respective schools, and nearly 40 other institutions of higher learning have carried on trial works of single sport level standard, such as sports aerobics, and cross-country orienteering etc., and achieved preliminary results. Taking Peking University as an example, since 2010, in classroom teaching assessment, it has selected 10 projects for trial out, and in 2010-2011, 17\% of students had received sports level certificates (Table 1), and 22\% of students obtained different grade certificates in various types of school competition (Table 2), and in the 48 sports societies or associations, 15 had been selected for trial out of the "Sports Level Standards (Table 3).

\section{Enhance Students’ Physical Quality-Put up "Student Physical Health and Sunshine Sports Management Platform”}

\section{Implementation Background}

In 2011, the General Administration of Sport of China and the Ministry of Education jointly issued the "National Student Physical Quality and Health Survey Results”, which showed that the trend of continuous decline of the physical quality of primary and middle school students of China over the past 20 years had been contained for the first time. Nevertheless, the physical quality of college students still continued to declineof the college students groups aged from 19 to 22, their

Table 1.

Statistical number and percentage of students obtaining PE level sports certificates (2010-2011 school year).

\begin{tabular}{lccc}
\hline & $\begin{array}{c}\text { Total Number of } \\
\text { Students }\end{array}$ & $\begin{array}{c}\text { Standard } \\
\text { Quota }\end{array}$ & $\begin{array}{c}\text { Standardization } \\
\text { Rate }\end{array}$ \\
\hline $\begin{array}{c}\text { Number of People } \\
\text { and Percentage }\end{array}$ & 7890 & 1470 & $17 \%$ \\
\hline
\end{tabular}

Table 2.

Statistical percentage of number of students obtaining sports level standard certificate in various types of school competition (2010-2011 school year).

\begin{tabular}{lccccc}
\hline & $\begin{array}{c}\text { Master } \\
\text { sportsman }\end{array}$ & First-class & Second-class & Third-class & Total \\
\hline Percentage & $0 \%$ & $3.1 \%$ & $7.3 \%$ & $12.2 \%$ & $22.6 \%$ \\
\hline $\begin{array}{l}\text { Table 3. } \\
\text { List of sports societies or associations of sports level trial out. }\end{array}$
\end{tabular}




\begin{tabular}{ll}
\hline Category & Society or Association \\
\hline Standard Items & $\begin{array}{l}\text { Runners Association, Swimmers Association, } \\
\text { Directional Association, and Mountaineering } \\
\text { Association }\end{array}$ \\
& $\begin{array}{l}\text { Football Association, Basketball Association, } \\
\text { Volleyball Association, Baseball and Software }\end{array}$ \\
Event Ranking & Association, Table Tennis Association, Badminton \\
Type Items & $\begin{array}{l}\text { Association, Tennis Association, And Jing Wu } \\
\text { Sports Association }\end{array}$ \\
Event Ranking and & Aerobics Association, Taijiquan Association, Sports \\
Standard Type & Dance Association \\
Items & \\
\hline
\end{tabular}

physical quality indexes, such as explosive force, strength and endurance, demonstrated a marked decline. This was no doubt a wake-up call to sports management and scientific research personnel of higher learning institutions: how to reform physical education in higher learning institutions, and contain the trend of decline of the physical health standard of college students.

In August 2002, the Ministry Of Education and the General Administration of Sport of China jointly issued a documents (Jiao Ti Yi, 2002: No. 12), demanding that "starting September 2002, pilot experiment on "Student Physical Health Standard" (referred to as "Standard" hereinafter) will be carried on in some schools nationwide. In October of the same year, Peking University participated in training on the implementation of the "Standard" organized by the Beijing Municipal Commission of Education, and became a pilot school of Beijing municipality to implement the "Standard". In 2007, on the basis of integration of the preliminary trial experiences, the Ministry of Education and the General Administration of Sport of China issued the "National Student Physical Health Standard" (referred to as "New Standard" hereinafter), expanded the test items, improved the evaluation standard, and put forward new requirements on works of students' physical quality and health testing.

\section{Reform Measures}

In the six years of implementation of the "Standard", through continuous exploration, Peking University had created a test management system with "Peking University characteristic", and walked ahead of the national institutions of higher learning. In the process of implementation, it not only focused on implementation of the "Standard" test itself, but also, with this as means, let more students go to the playground, to nature, under the sunshine, to actively participate in sports exercise, cultivate their sports training interests and habits, make campus sports exercise a common practice, so as to genuinely improve the physical health level of students. In 2002, Peking University implemented the "Student Physical Health Standard", which was later renamed to the "National Student Physical Health Standard". Physical health assessment work implemented networking and systematic management, and P.E teachers realized "zero workload"; in 2007, physical health assessment was incorporated into the physical education curriculum management. In 2011, "Student Physical Health Standard” was regular promulgated college and department rankings, freshman data higher level reporting, joint construction of practical training base with specialized unit in order to solve the problem of degree of professionalization of testing personnel, and fostering of professional testing team; in order to realize timely feedback of the student assessment results, Health Center of the Department of
Physical Education of Peking University set up the "Student Physical Health and Sunshine Sports Management Platform”, realized site feedback of assessment results, and exercise intensity monitoring had realized immediate heart rate monitor after exercise, ensured spots effects, and achieved science fitness. In 2012, physical health assessment results are included in the student sports curriculum result.

\section{Reform Results}

The implementation of a series of reform measures have ensured professional, scientific and systematic physical health monitoring, and guaranteed the physical health monitoring effect. As a result, the physical health standard had realized steady improvement year after year (Table 4).

\section{Innovate and Prosper Campus Sports Culture- \\ Self-Education and All-Round Physical and Psychological Development of Student Sports Societies and Associations}

\section{Implementation Background}

In 2002, the Ministry of Education called for national college students to "do an hour physical exercise every day, enjoy healthy work for fifty years, and live a happy life lifetime”. In December 2006, the Ministry of Education and the General Administration of Sport of China launched the "Hundreds of Millions of Teenagers Sunshine Sports”. In May 2007, a document entitled "Opinion of the CPC Central Committee and the State Council on Strengthening Teenagers' Sport and Improving Teenagers' Physical Health” (Zhong Fa, 2007: No. 7) was released. In 2008, a conference entitled "Hundreds of Millions of Students Sunshine Nationwide Sports Promotion for Welcoming of the Olympic Games” was held in Zhangjiagang; the Ministry of Education forwarded the speech of Liu Yandong, a state councilor, and of Zhou Ji, Head of the Ministry of Education, delivered respectively on this nationwide school sports working conference. In 2011, the Sixth Plenary Session of the $17^{\text {th }}$ CPC Central Committee adopted the "Decision of the CPC Central Committee on Certain Major Issues concerning Deepening of Cultural System Reform and Promoting Socialist Cultural Great Development and Prosperity”, fully understand the importance and urgency of promoting cultural reform and development, and promote more consciously and actively socialist cultural great development and prosperity. Therefore, health, exercise; sunshine, and sports... in this new period, sports are endowed with more definite meaning and connotation, and to carry out "sunshine sports" and to prosper campus sport culture has all the more put up for college students a wonderful stage.

\section{Reform Measures}

The history of societies Peking University originated from the establishment of the "Anti-Russian Association of Blood"

Table 4.

Statistical table of assessment result of the "National Student Physical Health Standard” of students from Peking University (2007-2011).

\begin{tabular}{cccccc}
\hline Year & $\mathbf{2 0 0 7}$ & $\mathbf{2 0 0 8}$ & $\mathbf{2 0 0 9}$ & $\mathbf{2 0 1 0}$ & $\mathbf{2 0 1 1}$ \\
\hline $\begin{array}{c}\text { Qualification } \\
\text { Rate }\end{array}$ & $74.19 \%$ & $71.27 \%$ & $83.60 \%$ & $83.85 \%$ & $86.8 \%$ \\
\hline
\end{tabular}

in 1904, which was the first organization in its strict sense as we know today. Over the past hundred years, student organiza- 
tions or societies of the Peking University have always been proudly standing at the tide of progress of the times and writing the brilliance of the PKU campus culture. These colorful organizations provide students with a broad stage, and their diversity and interests help students realize their dreams of demonstration of talents and cultivation of hobbies, and the organization or community characteristics of self-management, selfeducation and self-service also meet very well the needs of students for self-training and all-round development. As of September 2011, there were a total of 260 or so PKU communities or organizations, of which, 48 are sports fitness organizations, which is the largest in terms of single subject communities.

PKU sports organizations have the following outstanding characteristics: scaled hierarchy, diversified projects, high degree of man-times participation, high level operation, more events activities, high aim and broad vision, flexible schedule, relatively sufficient funds, fixed venue with instructors and unit, and most of the societies or organizations have their own publications or websites and online discussion. It is precisely these characteristics that ensure the smooth and effective development of "sunshine sports" plan in the PKU campus.

In the investigation and research of sport activities carried out towards sport organizations of PKU, it is found out that $100 \%$ of the sport organizations organize large or medium scale events and activities each semester, and students participating in the activities of these sport organizations each year can reach as high as 20,000 man-times, and these reflected very well the sunshine sports spirit and quality education and the overall fitness requirements. In the investigation and research of the sport organizations, it is also discovered that the scale of $25 \%$ of these organizations have more than 300 people, $50 \%$ between 100 - 300 people, and $25 \%$ less than 100 people; $30 \%$ of these sport organizations have more than 2 activities each week, $65 \%$ have 1 - 2 activities each year; $86 \%$ of these organizations have fixed time for routine activities, and usually during extracurricular activities at noon time, afternoon, evening or during weekends; usually focused on the noon, afternoon, evening and extracurricular activities time weekend; they are dynamically arranged according to the time of cadres of their associations and community members; $90 \%$ of these communities or organizations have fixed venue for activity, and $95 \%$ of them have their own publications or websites.

\section{Reform Effects}

1) Universal Functions of Societies or Organizations

Sport organization, as a mode of practice with great significance that integrates the life and education of college students, is an important component of physical education of higher learning institutions. It provides a wide space for the free development of interests of students, improving interpersonal relations, and cultivating healthy psychological qualities. It is not only the need of the student's ego-subject, but also the need of the school for promotion of quality education in an all-round way. It represents effectively the school physical education functions, and has a great significance in optimizing physical education in higher learning institutions and promoting modernization of higher education.

2) Mutual Promoting Relations between Organizations and Physical Education Curriculum

In 45 sports organizations, 36 have very high relevancy with their curriculum setup, which means that the sports items car- ried out by these organizations or societies are all included in the more than 40 physical education courses already set up in PKU or their extension. This indicates that these physical education courses lay the technical and mass foundation for these students, and at the same time their organizations or societies propagate and extend these courses, realizing therefore inside and outside class integration. In addition, sports items carried out by other 9 organizations or societies are not carried on in the physical education curriculum of PKU, such as aikido, karate, overall health association, golf association, and bicycle association etc., and their appearance is organic complementation to the physical education curriculum of the university, which demonstrates the diversity of sports fitness of PKU and meets the different needs of the students.

3) Promoting Relations between Organizations and Sport Competition

Sports societies or organizations are reserve resources of the sports team of the institutions of higher learning, and in some sports items, the higher learning institution itself does not set up a sports team. However, once there is completion task, it is the sports organizations that have carried on relatively better and effective activities in the school to set up a sports team and participate in the competition on behalf of the school. This not only solves the problem of shortage of fund for sports team construction of the school, but also meets the aspiration of these students to participate in the competition.

4) Promoting Relations between Organizations and Talent Training

Association culture reveals the disposition and quality of famous higher learning institutions. In comparison with the world first-class university, such as Harvard University, it has a total of 500 registered societies or school communities. Taking the United States as an example, of the elite characters in government, business, military, science, and art circles churned out from universities, majority are activists of community activities, such as Richard Nixon, John F. Kennedy, Bill Clinton, George $\mathrm{W}$. Bush and so on, all the whom were influential figures of student organizations. The Mountaineering Association of Peking University (MAPKU), under the guidance of the principle of "advancing to nature, conquering the self, braving danger, forging ahead, and pursuing for excellence”, carried on various forms of activities, including mountain climbing, scientific expedition, and rock climbing etc., and have trained a large number of young mountaineering enthusiasts and national mountaineering athletes, making their own contributions for China's folk mountaineering and high mountain scientific research undertakings. In 20 years time, they have successfully climbed 21 snow mountains with an altitude of $5000 \mathrm{~m}$. Of which, Zhao Lei with School of Physics of PKU, a senior member of the MAPKU, has become a coach of the China Climbing Team, and trained out several world champions; Sun Bin, another senior member of MAPKU, was the person-incharge for the torch relay in Qomolangma (Mount Everest) of the 2008 Beijing Olympic Games, and so on.

5) Promoting Relations of Reform of Organization and Sports Games

Development of the various sports organizations has injected school sport games and cultural festivals with new energy and vitality. For instance, during the parade of the school sports games, sports organizations form their own square formation one after another, holding their association flag and demonstrating their own spectacular skills and this has become the 
highlight of each session of school sports games. At the same time, different associations or organizations have developed some relatively classical and interesting sports competition items in their training and activities, and these have provided the sports games with very good raw materials and mass bases, and they are introduced to the games year after year and have become items of completion and performance of the campus sports games.

6) Train Excellent Student Referee Team

Another function of the sports associations or societies of PKU is that they have cultivated a group of community backbones to become referees of various sport events. These organizations have not only strengthened the physical qualities and physical and psychological health of its members, but also trained a batch of excellent referees for various sports events in order to facilitate organization of sports competitions. For instance, associations, such as football association, basketball association, badminton association, table tennis association, tennis association and taekwondo association etc., cultivate more than 40 the national level three referees, more than 20 national level two referees, and 3 to 5 national first level referees. Meanwhile, they have also churned out many amateur referees of various sports programs. They have played a very important role for successful holding of all kinds of small or big matching events in the school. At the same time, a lot of students continue their profession as referee after getting out of school, and therefore continue their own contributions for the mass sports.

\section{Conclusion and Recommendations}

To improve the quality of higher education, carry on sunshine sports, and enhance students' physical quality, all these need continuous reform and innovation: applying "Common
Student Sports Level Standard” to perfect the teaching evaluation system; making use of the physical health management platform to promote physical quality monitoring management; improving the physical health level through development of sports associations or organizations; emphasizing the students' selfeducation; paying attention to all-round development, and promoting prosperity and development of university campus sport culture. To deepen physical education reform in institutions of higher learning through the three means is an effective measure for physical education reform and development of institutions of higher learning under the great education concept.

To deepen physical education reform of institutions of higher learning and to realize system and institutional innovation is the key and difficult point for future development. In the future, only when physical education in institutions of higher learning truly becomes an important component of campus cultural construction can we fully realize the historical mission that physical education in institutions of higher learning is to be rooted on the cultivation of man, to carry out scientific research, to serve the society, and to transmit culture.

\section{REFERENCES}

Hu, J. T. (2011). Speech for Celebration of the 100th Founding Anniversary of Tsinghua University.

Ministry of Education of the People's Republic of China (2010). National Outline for Medium- and Long Term Educational Reform and Development (2010-2020).

General Office of the State Council (2007). Opinion of the CPC Central Committee and the State Council on Strengthening Teenagers' Sport and Improving Teenagers' Physical Health. 